\title{
Research and Application of Internet of Things in Intelligent Library
}

\author{
Tongjun Wang ${ }^{\text {a }}$, Peijun Zhao \\ Xin Yang College of Agriculture and Forestry, XinYang 464000, China \\ awangtongjun12345@126.com
}

Keywords: Internet of Things; RFID; intelligent library.

\begin{abstract}
The application and popularization of internet of things technology fundamentally change management operation mode and service model of libraries in colleges and universities. Internet of things intelligent library system in colleges and universities is constructed on the basis of information items, independent network and intelligent application technology architecture. Traditional library and intelligent library based on Internet of Things are compared. Quality and efficiency of book management can be greatly increased in intelligent libraries of colleges and universities based on internet of things.
\end{abstract}

\section{Introduction}

Rapid development and rapid popularization of Internet have great influence on college and university campus construction, education teaching model, teacher-student learning and lifestyle with technology innovation and rapid development of Internet and information industry since the 1990s, and colleges and universities comprehensively entered digital era ${ }^{[1]}$. Internet technology and mobile communication networks are developed deeply and continuously, thereby driving formation and development of network technology-Internet of Things of new generation. The measure will promote research and construction of new generation intelligent digital campus, thereby providing bene-facial conditions for efficiently integrating college digital resources and information systems, and better serving work, learning and daily life of the majority of teachers and students. Therefore, application of internet of things in intelligent library should be researched in the paper.

\section{Overview of Internet of Things}

RFID refers to radio frequency identification technology, which belongs to more advanced contactless identification technology started in the 1990s. A set of complete RFID systems include electronic tags, reader, data transmission system, processing system, etc. Currently, RFID electronic tags are applied in the library field to replace traditional bar code and magnetic stripe. RFID technology can be utilized for achieving self-help lending-borrowing services of books, thereby greatly reducing workload in the aspects of sorting, arranging, storing and counting books. National Library of Singapore is the first foreign liability to apply RFID technology ${ }^{[2]}$. Shenzhen Library is the first domestic library to apply RFID technology with the largest scale ${ }^{[3]}$. They explored and practiced the ape-plication of RFID technology in library, which are advanced currently. More and more libraries are introducing or intend to introduce RFID systems with more and more cheap price of RFID electronic tags. Although RFID technology is known as vanguard of Internet of Things technology, RFID systems applied in library cannot be called Internet of Things at present. Technical architecture of Internet of Things is still lack of significant perception layer, RFID reader only can be regarded as sensing point at most, and ubiquitous sensing network is not established ${ }^{[4]}$. RFID technology is introduced on the basis of existing digital library technology, which belongs to one improvement of existing library system in the aspect of internet of things, and it is the initial stage of internet of things.

RFID consists of three parts: an electronic tag (Tag), reader (Reader) and antenna (Antenna), wherein electronic tag chip is provided with a data storage area for storing and identifying object identifying information. Electronic tag is attached to or embedded on to-be-identified objects for 
identifying target objects. Reader is used for writing identifying information of to-be-identified object in agreed format into storage area of electronic tags (write-in function), or information stored in electronic tag can be read through contactless form in the reading scope of reader (read-out function $)^{[5]}$. Readers can be divided into hand-held mode or fixed mode. Antenna is transmitting and receiving device between tag and reader. Antenna and reader can be integrated as a whole, which can exist independent-lee. Any RFID system at least comprises one antenna, which may be built-in antenna or external antenna for receiving and transmitting radio frequency signals ${ }^{[6]}$.

\section{Technical Architecture of Internet of Things}

Internet of Things establishes IOT concept model through object, network and application three-dimensional model. IOT technical architecture is composed of information object, intelligent object, independent network and intelligent application as shown in figure 1

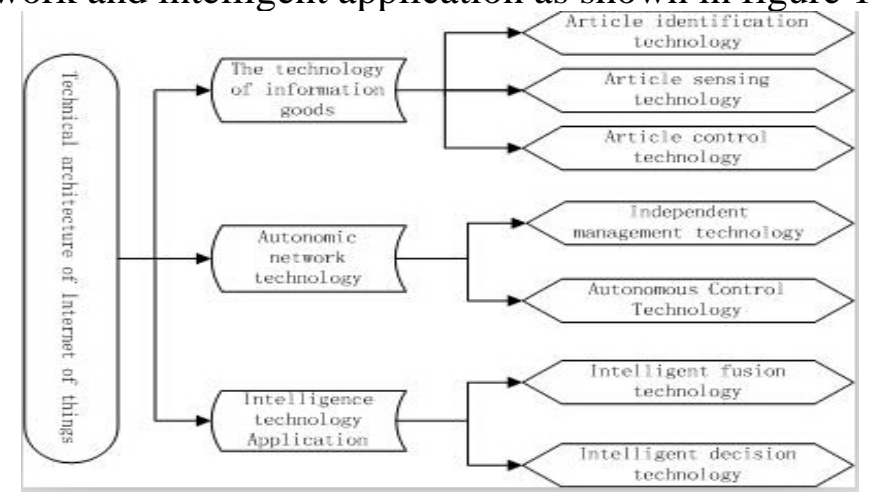

Fig. 1 IOT Technology Architecture

Information object technology mainly refers to object identifying, sensing and controlling technology, namely existing digital technology. Independent network refers to network system with self-management ability. Self-management ability is specifically manifested into self-configuration, self-healing, self-optimization, self-protection ability and intelligent application technology, including intelligent data fusion and intelligent decision-making control technology. Intelligent data fusion technology includes policy-based data integration, location-based data integration, time-based data integration and semantic-based data integration. Intelligent decision-making control technology includes intelligent-algorithm-based decision, policy-based decision and knowledge-based decision. These decision technologies should be supported by data mining technology, knowledge generation, knowledge updating, knowledge retrieval and other technologies. In the paper, three-layer technical architecture of IOT is applied in managing library of colleges and universities and constructing IOT library system in colleges and universities.

\section{Application of IOT in Library}

Emergence of IOT technology has generated huge impact on library business management model, which improves automated management model, achieves humane services, and enhances work efficiency. The entire IOT library is divided into three parts of information object, independent network and intelligent application as shown in Figure 2 according to IOT technical architecture.

Information Object. Library literature resource belongs to information object with the highest use frequency in library; information objects also include some hardware facilities in the library, such as security access control, etc. Literature barcodes are mainly scanned through reader from electronic tag pasting to literature data. Data acquired through RFID technology will be sent into library automation management system, namely independent network.

Independent Network. Independent network refers to network system with self-management ability. Self-management ability is specifically manifested into self-configuration, self-healing, self-optimization and self-protection capabilities. Independent network of library is evolved from original library automation management system, including library card system, lending and 
borrowing system, book retrieval, book updating system and other daily management. The independent network can independently manage library through library automatic management system, thereby improving automatic management mode of library. Meanwhile, independent network is also provided with intelligent management functions, which can intelligently manage various user terminals.

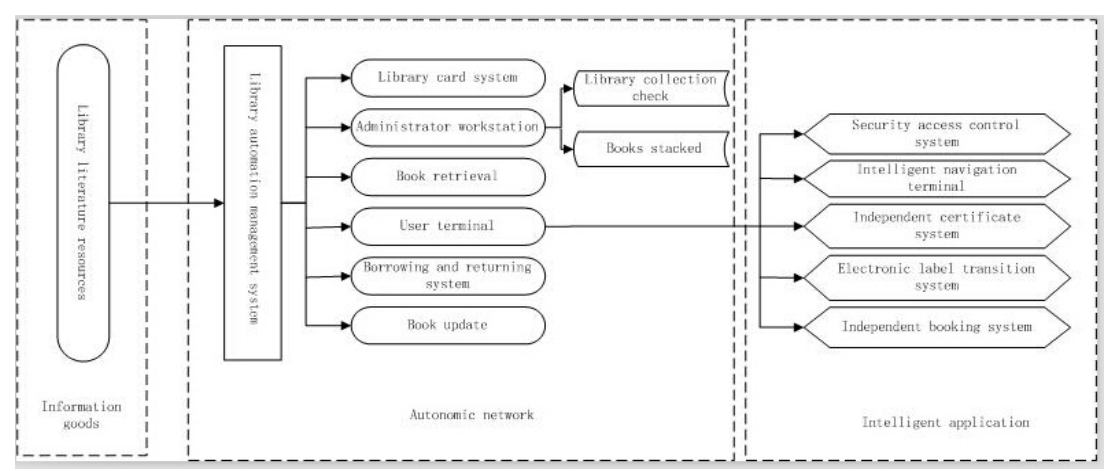

Fig.2 University library system architecture of Internet of Things

Intelligent Terminal. Intelligent terminals include intelligent navigation retrieval terminal, security access control system, in-dependent accreditation system, electronic tag conversion system and independent appointment lending and borrowing system, etc. They can help readers to use library literature resources faster and more simply, thereby improving resource utilization rate of libraries

\section{Advantages}

Document Entry. After IOT technology is used, RFID technology can be utilized for recording document literature into library automatic management system during literature procurement. Catalogers can borrow and use the literature only through attaching literature storage location and electronic tags behind the literature. We can upload massive literature data into library automatic management system through RFID technology with procurement of massive literature into library, thereby improving racking efficiency of literature.

Book Inventorying. When the library is closed, books should be inventoried frequently, which are mostly completed manually in the past, thereby wasting time. In IOT library, librarians can acquire book information data only through using RFID handheld reader for scanning RFID tags of books on the shelves. Meanwhile, acquired data can be returned back to library automatic management system through antenna, which can be backed up. Secondly, the automatic management system can adopt backup data to match with original data for detection. Text can be automatically generated by document literature which cannot be matched in backup data and original data, which can be submitted to administrator. Meanwhile, the data can be submitted to independent appointment borrowing and return-in system. Input data can be matched with original data through the system, and the system data can be updated for preventing borrowing conflict after matching is completed. Then, literature resources of library can be lent by librarians after being scanned with reader. Scanned literature resource record can be transmitted back to back-end database, and lags of corresponding fields can be modified. Lending literature data information can be acquired through database condition query. Finally, librarians can count and check lending record and literature remaining records which are returned after the shelves are scanned. Library inventorying task can be completed through four steps, which are realized basically through independent network in the inventorying process, thereby saving a lot of time and human resources.

Book Circulation. Reader can inquire own desired books through intelligent navigation retrieval terminal during book borrowing and returning. Storage locations of own desired books can be conveniently and easily founded according to inquiry result. Meanwhile, IOT library also can provide self-help appointment borrowing and lending system, for example, you can appoint your desired book through the intelligent terminal if your desired book has been borrowed. IOT library adopts RFID technology. Meanwhile, security access control systems are set. If the book carried by the reader is borrowed through normal rules, the book's barcode will be temporarily demagnetized. When 
the book passes through the access control system, access control system will not alarm. If the book is randomly left from the library in violation of borrowing rule, access control system will automatically alarm. Therefore, document literature of library can be well protected.

Perfect Personalized Services. Essence of personalized service lies in reflecting user-centric service philosophy. Users can acquire desired resources and services without limitation on time, space and mode. Personalized services of IOT library are manifested in the follows: library resource and facility management, optimization and maintenance are linked with information system under independent network environment, thereby realizing integration between library resources and data in information system, and optimizing library management and services. The network information resources are organically combined with library resources, thereby providing users with more and more comprehensive information resource. User book borrowing information is organically combined with library resource information. User use information is combined with library resource information, thereby recommending information re-sources related with borrowing information for users in real-time. Users also can acquire his desired information resources at any time anywhere through various user terminals.

Management of Library Building Facilities. Library IOT will integrate library security and fire-fighting systems. Library facility management is more secure and efficient. Hidden danger of facilities can be discovered in time. Meanwhile, library IOT also contains environment monitoring, public health surveillance and other systems, thereby users can learn more safely in library.

Work Quality and Efficiency. Labor efficiency of library staff can be improved, and statistical work can be provided with more scientific basis under assistance of library IOT. Work quality can be improved. Surely, IOT has many advantages when it is applied in library, such as provision of human services, simplification of library organization, reinforcement of librarian quality, etc.

\section{Summary}

In the paper, the concept of IOT and its three-dimensional model are applied to college libraries; three-layer architecture of IOT library system is con-strutted. Meanwhile, main functions in all layer architectures are described. IOT library is compared with current library, IOT library has many advantages. Meanwhile, application of IOT in library significantly improves resource utilization rate of library. Application of IOT technology, especially RFID technology, in libraries makes library automatic and intelligent. IOT library will become a new milestone in library development course.

Name of the fund: Young teacher's research funded projects for XINYANG College of Agriculture And Forestry (201301005).

\section{References}

[1] Ren Xiaoli. Design of intelligent bus system based on Internet of things. Electronic Design Engineering.2013, 21(12):p. 60-62.

[2] Sun Qibo, LIU Jie, and LI Shan, et al. Internet of things: summarize on concepts, architecture and key technology problem. Journal of Beijing University of Posts and Telecommunications. 2010, 33(3): p. 1-9.

[3] Dong Xiaoxia, Gong Xiangyang, Zhang Ruolin, et al. The Design and Implementation of the Smart Library based on the Internet of Things. Library Journal.2011, 30(3):p. 65-68.

[4] Zhang YuSong. Research on Subject Service in Library based on Internet of Things Technology. Journal of Library and Information Sciences in Agriculture.2013, 25(12):p. 175-177.

[5] Ma Jianxun, Yang Guolin. Application of the Three-tier Architecture of Internet of Things in the University Library. Journal of Inner Mongolia University of Technology. 2012, 32(2): p.45-49.

[6] Li Junhua. Analysis and Design of Intelligent Digital Campus Based on the Internet of Things. Journal of Wuzhou University.2010, 20(3):p. 49-54. 